\title{
Phase 2 dose-ranging study of the virologic efficacy and safety of the combination COVID-19 antibodies casirivimab and imdevimab in the outpatient setting
}

Cynthia Portal-Celhay, Eduardo Forleo-Neto, Will Eagan, Bret J Musser, John

D Davis, Kenneth C Turner, Thomas Norton, Andrea T Hooper, Jennifer D Hamilton, Cynthia Pan, Adnan Mahmood, Alina Baum, Christos A Kyratsous, Yunji Kim, Janie Parrino, Wendy Kampman, Lilia Roque-Guerrero, Roxana Stoici, Adil Fatakia, Yuhwen Soo, Gregory P Geba, Bari Kowal, A Thomas DiCioccio, Neil Stahl, Leah Lipsich, Ned Braunstein, Gary A Herman, George D Yancopoulos, David M Weinreich, Study Investigators*

Regeneron Pharmaceuticals, Inc., Tarrytown, NY, USA (C Portal-Celhay MD, E Forleo-Neto MD, W Eagan PhD, BJ Musser PhD, JD Davis PhD, KC Turner PhD, T Norton MD, AT Hooper PhD, JD Hamilton PhD, C Pan BPharm, A Mahmood MD, A Baum PhD, CA Kyratsous PhD, Y Kim PharmD, J Parrino MD, W Kampman MD, Y Soo PhD, GP Geba MD DrPH, B Kowal MS, AT DiCioccio PhD, N Stahl PhD, L Lipsich PhD, N Braunstein MD, GA Herman MD, GD Yancopoulos MD, DM Weinreich MD); Bio-Medical Research, LLC, Miami, FL, USA (L Roque-Guerrero MD); Global Clinical Professionals Research, St. Petersburg, FL, USA (R Stoici MD); Tandem Clinical Research, LLC, Marrero, LA, USA (A Fatakia MD)

${ }^{*}$ Clinical Trial Investigators listed in the Appendix 


\section{Summary}

Background The monoclonal antibody combination casirivimab and imdevimab $\left(\right.$ REGEN-COV $\left.{ }^{\circledR}\right)$ reduced viral load, hospitalisation, or death when administered 1:1 as an intravenous (IV) dose $\geq 1200 \mathrm{mg}$ in a phase 3 COVID-19 outpatient study. Availability of subcutaneous (SC) and/or lower IV doses should increase accessibility and/or drug supplies for patients.

Methods This is a double-blind, placebo-controlled study of SARS-CoV-2-infected outpatients who were asymptomatic, or symptomatic but without risk factors for severe COVID-19. Patients were randomised to single IV dose (517 patients) of REGEN-COV 300, 600, 1200 or $2400 \mathrm{mg}$ or placebo; or a single SC dose (286 patients) of REGEN-COV 600 or $1200 \mathrm{mg}$ or placebo. The primary endpoint was time-weighted average daily change from baseline (TWACB) in viral load from day 1 (baseline) through day 7 in patients seronegative to SARS-CoV-2 at baseline.

Findings All REGEN-COV treatments showed significant $(p<0.001$ versus pooled placebo) virologic reduction through day 7 . Least-squares mean differences in TWACB viral load for the treatments versus placebo ranged from -0.56 to -0.71 $\log _{10}$ copies $/ \mathrm{mL}$. Each REGEN-COV treatment showed significant $(p<0.001$ versus pooled placebo) and similar virologic reduction through day 7 . There were no safety concerns, dose-related safety findings, grade $\geq 2$ infusion related/hypersensitivity reactions, grade $\geq 3$ injection-site reactions, nor fatalities. Two serious adverse events not related to COVID-19 or the study drug were reported. 
Interpretation: In asymptomatic and low-risk symptomatic SARS-CoV-2-infected outpatients seronegative for antibodies against SARS-CoV-2 at baseline, REGENCOV significantly and comparably reduced viral load at all IV and SC doses.

Funding: Regeneron Pharmaceuticals, Inc. and Hoffman-La Roche Keywords: COVID-19, casirivimab, imdevimab, REGEN-COV, viral load, pharmacokinetics, intravenous, subcutaneous, neutralising antibodies, monoclonal antibodies 


\section{RESEARCH IN CONTEXT}

\section{Evidence before this study}

Early phase 1/2 data in coronavirus disease 2019 (COVID-19) outpatients (NCT04425629) found that the REGEN-COV ${ }^{\circledR}$ antibody combination, casirivimab and imdevimab, administered 1:1 as a single intravenous (IV) dose of $2400 \mathrm{mg}$ or $8000 \mathrm{mg}$ significantly reduced viral load over the first week compared to placebo. Enhanced viral clearance was more pronounced in patients who were seronegative for antibodies against severe acute respiratory syndrome coronavirus 2 (SARS-CoV2), or who had high viral load at baseline. The phase 3 portion of this outpatient treatment study subsequently evaluated $1200 \mathrm{mg}$ IV and $2400 \mathrm{mg}$ IV doses, demonstrating consistent virologic efficacy, further demonstrating that REGEN-COV treatment reduced risk of COVID-19-related hospitalisation or all-cause death, and shortened time to symptom resolution. Virologic clearance was similar among those treated with any of the three doses $(8000 \mathrm{mg}, 2400 \mathrm{mg}$, or $1200 \mathrm{mg})$; therefore, maximal virologic efficacy may have been achieved at the $1200 \mathrm{mg}$ dose in this treatment setting. These results warranted investigation of lower dose regimens.

\section{Added value of this study}

The present dose-ranging study evaluated whether a lower dose regimen could demonstrate virologic efficacy similar to that observed with $1200 \mathrm{mg} \mathrm{IV}$ and $2400 \mathrm{mg}$ IV doses in outpatient treatment study. Exploration of a wider dose range will provide further characterisation of the clinical effects of REGEN-COV. Moreover, identifying a lower efficacious dose could bolster the ability to provide an adequate therapeutic supply of REGEN-COV in the setting of a global pandemic. A $1200 \mathrm{mg}$ subcutaneous (SC) dose of REGEN-COV also prevented COVID-19 in household 
contacts of SARS-CoV-2-infected individuals (NCT04452318). The availability of a SC regimen could improve access for patients who have confirmed SARS-CoV-2 infection but for who IV infusion is not feasible.

\section{Implications of all the available evidence}

Despite the growing number of therapeutics with authorisation or approval for the treatment and/or prevention of COVID-19, there remains a significant global need for effective COVID-19 therapies. Additional therapeutics and dosing regimens will be required to meet demand and to meet the needs of specific patient populations.

Lower IV doses of REGEN-COV, and the option of SC administration, should increase accessibility for patients. This increased availability needs to be weighed against several unanswered questions, including 1) whether the correlation between decreased viral load in the nasopharynx and improvement in clinical outcome holds at lower doses of REGEN-COV, and 2) whether the reduced drug exposure margins are sufficient to prevent viral escape and emergence of variants of concern.

Word count: 407 (no word count limit) 


\section{Introduction}

Severe acute respiratory syndrome coronavirus 2 (SARS-CoV-2) first emerged in 2019 and is the causal agent of coronavirus disease 2019 (COVID-19), responsible for a world-wide pandemic. ${ }^{1}$ While some patients remain asymptomatic, others affected by COVID-19 are at risk of developing a range of respiratory conditions, from mild symptoms to severe and often fatal respiratory illness. ${ }^{2,3}$ Several factors, including age, pregnancy, race or ethnicity, and certain comorbidities (such as obesity, diabetes, cardiovascular disease, sickle cell disease, and chronic lung disease), place patients at high risk of more serious illness and increased hospitalisations. ${ }^{4-6}$ Recent studies among hospitalised patients found that high SARS-CoV-2 viral load is associated with increased mortality rates. ${ }^{7,8}$ Although similar studies are limited in the outpatient setting, such findings suggest that a SARS-CoV-2 antiviral therapy given to outpatients may reduce the risk of hospitalisation or death due to COVID-19.

All coronaviruses have spike $(S)$ proteins that mediate entry into host cells by binding to angiotensin-converting enzyme 2 (ACE2) with high affinity. ${ }^{9}$ Blockade of host cell entry using neutralising antibodies against $S$ proteins is one mechanistic strategy to reduce the pathogenesis of SARS-CoV-2. ${ }^{10}$ Casirivimab (REGN10933) and imdevimab (REGN10987) are human, immunoglobulin G1 monoclonal antibodies (mAbs) that simultaneously bind the receptor-binding domain of the SARS-CoV-2 S protein to block interaction with ACE2. In vitro and preclinical studies have shown that these two antibodies, administered together, minimise viral escape due to multiple SARS-CoV-2 mutations. ${ }^{11-13}$ These results point to a promising therapeutic approach of co-administering the antibodies 1:1 (REGEN-COV ${ }^{\circledR}$ antibody 
combination) to reduce both the viral load of SARS-CoV-2 and COVID-19 disease progression.

In a phase 1/2 study outpatients positive for SARS-CoV-2 (NCT04425629), we previously reported that a single intravenous (IV) dose of REGEN-COV $2400 \mathrm{mg}$ or $8000 \mathrm{mg}$ reduced viral load, with a greater effect in patients who had not yet mounted an immune response (seronegative) or who had a high viral load at baseline. ${ }^{14}$ Based on these data, in November 2020, the $2400 \mathrm{mg}$ IV dose of REGEN-COV received Emergency Use Authorization (EUA) from the United States Food and Drug Administration for the treatment of mild-to-moderate COVID-19 in adults and paediatric patients (aged 12-17 years, weighing $\geq 40 \mathrm{~kg}$ ) who had positive SARS-CoV-2 viral testing and who were at high risk of progressing to severe COVID-19. ${ }^{15}$ At the same time that the trial described in this report was initiated, the phase 3 portion of the above outpatient treatment study (NCT04425629) using 1200 mg IV and $2400 \mathrm{mg}$ IV doses confirmed the previous findings and further showed that REGEN-COV significantly reduced the risk COVID-19-related hospitalisation and all-cause death, as well as decreased the duration of symptoms. Therefore, in June 2021, based on data from the study presented in this report as well as the those presented above, the $1200 \mathrm{mg}$ dose of REGEN-COV administered IV or SC received EUA for treatment of mild-to moderate COVID-19 and post-exposure prophylaxis in individuals who are at high risk for progression to severe COVID-19. ${ }^{16}$

A SC route of administration and lower doses could increase accessibility and supplies of drug. This current study evaluates the virologic efficacy and the safety of a range of IV and SC doses of REGEN-COV in outpatients with asymptomatic 
medRxiv preprint doi: https://doi.org/10.1101/2021.11.09.21265912; this version posted November 10, 2021. The copyright holder for this preprint (which was not certified by peer review) is the author/funder, who has granted medRxiv a license to display the preprint in perpetuity.

It is made available under a CC-BY-NC-ND 4.0 International license .

SARS-CoV-2 infection, or symptomatic with no risk factors for progressing to severe COVID-19. 


\section{Methods}

\section{Trial design}

This phase 2, randomised, double-blind, placebo-controlled, parallel-group, doseranging study (NCT04666441) was conducted at 47 sites across the USA (see appendix 1 for a full list of the study sites and investigators and appendix 2 for the Regeneron study team).

Nasopharyngeal (NP) swabs and blood samples were collected from patients every other day for the first week. A phone visit occurred during the fourth week to collect safety information. After the first month, patients had monthly visits for 4 additional months. The final visit (end of study, day 169) was a phone call. Figure 1 depicts the schedule of events.

\section{Patients}

The study enrolled outpatients aged $\geq 18$ years with a positive SARS-CoV-2 diagnostic test (using a local SARS-CoV-2 antigen, quantitative reverse transcription polymerase chain reaction [RT-qPCR], or other molecular diagnostic assay) from a sample (such as NP, nasal, oropharyngeal, or saliva) collected $\leq 72 \mathrm{~h}$ prior to randomisation. Eligible patients were SARS-CoV-2 infected but either asymptomatic or symptomatic $\leq 7$ days before randomisation. Eligible symptomatic patients were required to be at low risk for developing severe COVID-19, defined as meeting all of the following criteria: body mass index $<30 \mathrm{~kg} / \mathrm{m}^{2}$; age $\leq 50$ years; not pregnant; and no cardiovascular disease or hypertension, chronic lung disease or asthma, type 1 or type 2 diabetes mellitus, chronic kidney disease, or chronic liver disease. Eligible asymptomatic patients, with or without risk factors, could not have symptoms 
consistent with COVID-19 currently or at any time $<2$ months prior to randomisation.

For the purposes of eligibility assessment, the presence or absence of COVID-19 symptoms was determined at the discretion of investigators. Immunosuppressed patents, as per the investigator's assessment, were excluded from the study.

\section{Intervention and assessments}

Eligible patients were randomised to receive a single dose of REGEN-COV or matching placebo administered by IV or SC route. Baseline (day 1) was the day of study drug or placebo administration. The IV single-dose regimens were REGENCOV 300 mg (150 mg per mAb), 600 mg (300 mg per mAb), 1200 mg (600 mg per $m A b)$ and $2400 \mathrm{mg}$ (1200 mg per mAb). The SC single-dose regimens were REGEN-COV $600 \mathrm{mg}$ (two injections of $300 \mathrm{mg}$ per mAb) and REGEN-COV $1200 \mathrm{mg}$ (four injections of $600 \mathrm{mg}$ per mAb). Each injection volume was $2.5 \mathrm{~mL}$. Healthcare providers, patients and their caregivers were blinded to placebo and the doses of REGEN-COV drug but not to the route of administration.

\section{Endpoints}

The primary endpoint was the time-weighted average daily change from baseline (TWACB) in viral load $\left(\log _{10}\right.$ copies $\left./ \mathrm{mL}\right)$ from day 1 to day 7 , as measured by RT-qPCR of NP swab samples, in patients who had a central-lab determined quantitative RT-PCR positive test at baseline and were seronegative (negative for anti-spike [S1] IgA, anti-spike [S1] IgG, and anti-nucleocapsid lgG) (see appendix 3 and 4 for further details on methodology).

Secondary endpoints included the evaluation of additional indicators of virologic efficacy, safety, and tolerability, as well as REGEN-COV concentrations in serum 
over time (see appendix 5 for pharmacokinetic analysis methods). The key safety variables included the incidence of all treatment-emergent adverse events (TEAEs) up to day 29 , grade $\geq 3$ TEAEs from day 30 and up to the end of the study (EOS), serious adverse events (SAEs) through EOS, and adverse events of special interest (AESIs). AESIs included all grade $\geq 2$ infusion related reactions through day 4 , grade $\geq 3$ injection-site reactions through day 4 , grade $\geq 2$ hypersensitivity reactions through day 29, and any TEAE that led to a hospitalisation, or an emergency room visit throughout the study, regardless of relation to COVID-19.

\section{Statistical analysis}

It was estimated that a sample size of 57 patients per treatment group would provide $98 \%$ power to detect a difference of $-0.73 \log _{10}$ copies $/ \mathrm{mL}$ (assuming a standard deviation [SD] of 0.948 ) between any active treatment group and pooled placebo (IV and SC). The assumed SD and targeted difference used for powering was based on the observed variability and treatment difference of time-weighted average measurements in a companion phase 2 study of REGEN-COV in the outpatient treatment setting. ${ }^{17}$ With the assumption that $50 \%$ of enrolled patients would be seronegative at baseline, the study randomised approximately 800 patients to enrol 400 seronegative patients for efficacy analyses (ie, 57 patients per treatment group).

The route of administration was not expected to alter pharmacodynamic response in patients who received placebo. The IV and SC placebo groups were therefore pooled for all virologic efficacy analyses. Active treatment groups were not pooled for any efficacy analysis. 
The overall modified full analysis set (mFAS) included all randomised patients who received treatment and who had a positive central-lab determined SARS-CoV-2 RT-qPCR result from NP swab samples at randomisation and was based on the treatment received. The primary analysis was conducted in the subset of patients in the overall mFAS who were seronegative at baseline for SARS-CoV-2 (seronegative mFAS). The efficacy analyses were based on observed data, with no imputation for missing data. The primary efficacy variable, TWACB, was calculated using the area under the curve (AUC) divided by the number of days (day 1 to day 7). AUC was calculated using the linear trapezoidal rule. Statistical analysis for viral load was conducted using a scale of $\log _{10}$ copies $/ \mathrm{mL}$. An analysis of covariance (ANCOVA) model with treatment group as a fixed effect, and baseline viral load and treatment by baseline interaction as covariates, was fitted to the data for analysis of the primary endpoint. The overall type I error was controlled at the $5 \%$ level via a prespecified hierarchical testing procedure (ie, comparison between each active treatment group and placebo was formally tested). Additional statistical analysis details are described in the appendix 6.

The safety analysis set (SAF) included all randomised patients who received any study drug, and the pharmacokinetic analysis set included all patients who received any study drug and who had $\geq 1$ non-missing drug concentration measurement following study drug administration.

\section{Role of the funding source}

This study was supported by Regeneron Pharmaceuticals, Inc., and Hoffman-La Roche. Certain aspects of this project were funded in whole or in part with federal funds from the Department of Health and Human Services, Office of the Assistant 
medRxiv preprint doi: https://doi.org/10.1101/2021.11.09.21265912; this version posted November 10, 2021. The copyright holder for this preprint (which was not certified by peer review) is the author/funder, who has granted medRxiv a license to display the preprint in perpetuity. It is made available under a CC-BY-NC-ND 4.0 International license .

Secretary for Preparedness and Response, Biomedical Advanced Research and Development Authority, under OT number: HHSO100201700020C.

\section{Study oversight}

Study oversight is described in the appendix 7. 


\section{Results}

\section{Participants}

A total of 815 patients were randomised and assigned to IV administration $(n=523)$ or SC administration ( $\mathrm{n}=292)$. Of those patients assigned to IV administration, 506 were SARS-CoV-2 positive via central-lab testing and therefore allocated to the overall mFAS; of those patients, 359 were seronegative at baseline for SARS-CoV-2 antibodies and therefore allocated to the seronegative mFAS. Of the patients assigned to SC administration, 304 were allocated to the overall mFAS, and 225 to the seronegative mFAS. In the analysis sets for efficacy (overall mFAS and seronegative mFAS), placebo IV and placebo SC are pooled, and this is reflected in the numbers presented above.

Of the seronegative mFAS patients assigned to IV administration, 80 were treated with $300 \mathrm{mg}$ REGEN-COV, 68 were treated with $600 \mathrm{mg}$ REGEN-COV, 72 were treated with 1200 mg REGEN-COV, 62 were treated with 2400 mg REGENCOV, and 77 were treated with placebo (pooled placebo group) (table 1) (see appendix, figure S1). For the IV group, the mean (SD) age was $34 \cdot 6$ (9.6) years, 44.6\% were male, $86 \cdot 1 \%$ were White, $3.9 \%$ were Black, and $33.7 \%$ identified as Hispanic or Latino ethnicity. The mean (SD) baseline viral load was $7.2(1.5) \log _{10}$ copies $/ \mathrm{mL}$, and $56 \cdot 8 \%$ of patients had a baseline viral load $>10^{7}$ copies $/ \mathrm{mL}$.

Of the seronegative mFAS patients assigned to SC administration, 75 were treated with $600 \mathrm{mg}$ REGEN-COV, 73 were treated with $1200 \mathrm{mg}$ REGEN-COV, and 77 were treated with placebo group (pooled placebo group) (table 1). For the total SC group, the mean (SD) age was 34.1 (10.0) years, $45.3 \%$ were male, $84.4 \%$ were 
White, $2 \cdot 7 \%$ were Black, and $34 \cdot 7 \%$ identified as Hispanic or Latino ethnicity. The mean (SD) baseline viral load was $7.2(1.5) \log _{10}$ copies $/ \mathrm{mL}$, and $56.9 \%$ of patients had a baseline viral load $>10^{7}$ copies $/ \mathrm{mL}$.

Patient demographics and baseline characteristics were generally balanced between the IV and SC groups and pooled placebo (table 1). This was also true of the overall mFAS $(n=712)$ and SAF ( $n=803$; data not shown). Approximately $92.5 \%$ of the IV patients and $91.3 \%$ of the SC patients in the SAF were low-risk symptomatic patients, and the remaining were asymptomatic. All patients included in this analysis had the opportunity to complete the primary endpoint visit to day 7. A total of 195 IV patients and 106 SC patients completed visits up to day 29 (SAF) as of the data cut-off of February 8, 2021.

\section{Viral load}

All REGEN-COV doses (SC and IV) significantly and similarly reduced viral load through day 7 versus pooled placebo (figure 2A). In the IV group, the least-squares mean (LSM) change in TWACB viral load ( $\log _{10}$ copies $\left./ \mathrm{mL}\right)$ between pooled placebo and REGEN-COV $(95 \% \mathrm{Cl})$ was $-0.71(-1.05,-0.38)(2400 \mathrm{mg}),-0.56(-0.89$,

$-0.24)(1200 \mathrm{mg}),-0.66(-0.99,-0.34)(600 \mathrm{mg})$ and $-0.57(-0.88,-0.25)$ (300 mg). All differences versus placebo were statistically significant (figure $2 A$ ). In the SC group, the LSM change in viral load between pooled placebo and REGEN$\operatorname{COV}(95 \% \mathrm{Cl})$ was $-0.56(-0.87,-0.24)(1200 \mathrm{mg})$ and $-0.56(-0.88,-0.24)$ (600 mg). All differences versus pooled placebo were statistically significant (figure 2A). All pairwise comparisons between active treatment groups including different routes of administration demonstrated similar treatment effects (figure $2 \mathrm{~B}$ ). 
All REGEN-COV doses (SC and IV) showed a similar reduction in viral load from baseline at each visit (figure 3). A difference in viral load between REGEN-COV treatments and pooled placebo was apparent by day $3,48 \mathrm{~h}$ after administration of the study drug. In the seronegative mFAS, the LSM differences $\left(\log _{10}\right.$ copies $\left./ \mathrm{mL}\right)$ from pooled placebo on day 3 in the IV treated groups were $-0.44(300 \mathrm{mg}),-0.74$ (600 mg), $-0.66(1200 \mathrm{mg})$ and $-0.53(2400 \mathrm{mg})$. The corresponding differences in the SC treated groups were $-0.34(600 \mathrm{mg})$ and $-0.49(1200 \mathrm{mg})$.

\section{Pharmacokinetics}

The concentration-time profiles for each antibody were essentially superimposable from day 1 to day 7 for any given dose; the mean concentrations of REGEN-COV in serum are therefore presented as the sum of total casirivimab and total imdevimab concentrations. After a single IV dose, antibody concentrations fell monotonically from day 1 to day 7 (figure 4). For the SC doses, the mean concentrations of REGEN-COV reached near maximal values by day 3, with peak concentrations attained at day 7 (figure 4).

There was no association between TWACB in viral load versus total drug concentration through day 7 for the active IV or SC REGEN-COV doses, suggesting that maximum effect on viral load was achieved at all dose levels (figure 5).

\section{Safety}

Overall, in the safety analysis population (all randomised patients who received any study drug), all IV and SC REGEN-COV doses showed low rates of adverse events when compared with placebo. No serious safety concern was reported, and no doserelated safety findings were observed; no deaths occurred during the study (table 2). 
One patient did not complete infusion of the study drug, due to a TEAE of a mild, grade 1 infusion reaction from the $2400 \mathrm{mg}$ IV dose, but the patient remained in the study. There were two SAEs reported in the $1200 \mathrm{mg}$ IV and $2400 \mathrm{mg}$ IV REGENCOV groups, both of which were considered unrelated to the study drug or COVID19. Both SAEs were miscarriages that occurred during the first trimester: one in primigravida and one in a patient with significant medical history of abortions. There were five additional pregnant women treated in study without any adverse outcome. No participant experienced a grade $\geq 2$ infusion related reaction or hypersensitivity reaction, or grade $\geq 3$ injection site reaction. The incidence of any TEAE that led to a hospitalisation or an emergency room visit (regardless of relation to COVID-19) was low, and none of the events were related to study treatment. 


\section{Discussion}

In this phase 2 dose-ranging study of asymptomatic or low-risk symptomatic, outpatients who were SARS-CoV-2 RT-PCR positive and SARS-CoV-2 antibody seronegative at baseline, REGEN-COV treatment resulted in a significant reduction in viral load (day 1 to day 7 ) versus placebo. Viral load showed similar reductions across all REGEN-COV treatments evaluated, including the lowest doses of $300 \mathrm{mg}$ (150 mg of each mAb) IV or $600 \mathrm{mg}$ (300 mg of each mAb) SC. Reduction in viral load occurred as early as $48 \mathrm{~h}$ after the treatment administration (day 3 of measurement), decreasing (versus placebo) at all doses, including patients treated with the $600 \mathrm{mg} \mathrm{SC}$ dose. Although maximal concentrations in serum were attained a few days later for SC than IV dosing, REGEN-COV was rapidly absorbed into the systemic circulation following SC administration and achieved concentrations that provided comparable maximal virologic efficacy to the IV doses at the earliest time point measured.

Incidences of TEAEs, SAEs, and AESIs were low and balanced across the active drug and placebo groups, suggesting no difference in the REGEN-COV safety profile across all dose levels tested, whether delivered SC or IV. The pharmacokinetics of each antibody were linear and dose-proportional. Additional pharmacokinetic/pharmacodynamic modelling is underway to further evaluate the relationship of drug concentration with changes in viral load, in order to characterise the effect of REGN-COV on NP SARS-CoV-2 viral dynamics.

As mentioned earlier, we reported similar results on viral load and safety in a phase 1/2/3 outpatient clinical outcomes study of REGEN-COV administered as a $1200 \mathrm{mg}, 2400 \mathrm{mg}$ or $8000 \mathrm{mg}$ single IV infusion (NCT04425629): ${ }^{14}$ the phase 3 
data show equivalent clinical and virologic outcomes in the outpatient setting for $1200 \mathrm{mg}$ and $2400 \mathrm{mg}$ of REGEN-COV. Moreover, the $1200 \mathrm{mg}$ SC dose demonstrated efficacy in a COVID-19 prevention and early treatment study of outpatients (NCT04452318). ${ }^{18}$ As a result of the totality of these data, Regeneron received an updated EUA for the treatment of mild-to-moderate COVID-19 and postexposure prophylaxis in individuals who are at high risk of progressing to severe COVID-19 with a single $1200 \mathrm{mg}$ IV or SC dose. ${ }^{19}$

The results of the present study suggest that the minimum dose for virologic efficacy may be lower than those evaluated. The current study did not determine whether the equivalent effect on reduction in viral load in the nasopharynx will correlate to similar improvements in clinical outcomes. In addition, while concentrations of each antibody on day 3 for the $600 \mathrm{mg} \mathrm{SC}$ dose are approximately 60 to several hundred times the concentrations required to neutralise wild-type SARS-CoV-2 virus and variants of concern in vitro, higher doses providing greater exposure margins are considered advantageous in the event that new variants emerge.

Despite the growing number of therapeutics with authorisation or approval for the treatment and/or prevention of COVID-19, there remains a significant global healthcare need for effective COVID-19 therapies. Multiple therapeutic and preventive agents are required to meet the demands and the needs of specific patient populations. Investigating different doses and methods of administration is key to characterising the dose-response for REGEN-COV and establishing a lower dose with similar effectiveness, while providing convenience for patients. Identifying lower doses that reduce viral load while not compromising clinical efficacy in 
preventing hospitalisation and death ensures the ability to provide therapeutics to as many individuals as possible.

In this analysis of low-risk patients (symptomatic with no significant risk factors, or asymptomatic) who were SARS-CoV-2 PCR-positive at baseline and seronegative, REGEN-COV significantly and comparably reduced viral load versus pooled placebo across all treatment groups, including at doses as low as $300 \mathrm{mg}$ IV or $600 \mathrm{mg}$ SC. REGEN-COV showed low levels of adverse events across all doses evaluated. Further studies are required to evaluate whether clinical outcomes remain the same with lower doses of REGEN-COV. 


\section{Contributors}

CPC, EFN, WE, BJM, JDD, KCT, TN, ATH, JDH, AM, AB, CAK, YK, JP, WK, YS, GPG, BK, ATD, NS, LL, NB, GAH, GDY, and DMW contributed to study concept and design. CP, LRG, RS, AF were involved in data collection. CP provided administrative, technical or material support. WE, BJM, YS provided statistical analysis. CPC, EFN, WE, BJM, JDD, KCT, TN, ATH, JDH, AM, GPG, GAH, GDY, and DMW provided analysis and interpretation of the data. CPC, EFN, WE, KCT drafted the manuscript. All authors provided critical revision of the manuscript for important intellectual content and provided approval to submit.

\section{Declaration of interests}

CPC, EFN, WE, BJM, JDD, TN, CP, AM, YK, JP, WK, YS, GPG, BK, ATD, LL, NB, and DMW are Regeneron employees/stockholders. KCT, JDH, and GAH are Regeneron employees/stockholders and have a patent pending, which has been licensed and receiving royalties, with Regeneron. $A B, C A K, N S$, and GDY are Regeneron employees/stockholders and have issued patents (U.S. Patent Nos. $10,787,501,10,954,289$, and 10,975,139) and pending patents, which have been licensed and receiving royalties, with Regeneron. ATH is a Regeneron employee/stockholder, former Pfizer employee and current stockholder, and has a patent pending, which has been licensed and receiving royalties, with Regeneron. LRG, RS, and AF have no conflicts to declare.

\section{Data sharing}

Qualified researchers may request access to study documents (including the clinical study report, study protocol with any amendments, blank case report form and 
statistical analysis plan) that support the methods and findings reported in this manuscript. Individual anonymised participant data will be considered for sharing once the product and indication have been approved by major health authorities (eg, FDA, EMA, PMDA, etc.), if there is legal authority to share the data and there is not a reasonable likelihood of participant re-identification. Submit requests to https://vivli.org/.

\section{Acknowledgements}

The authors would like to thank the patients and their families, as well as all other study investigators and all investigational site members involved in this study. Caryn Trbovic, PhD, S. Balachandra Dass, PhD, and Brian Head, PhD of Regeneron Pharmaceuticals Inc., and Michele Bipath, PharmD, of Prime Global, assisted with the development of the manuscript. Helen Kang, PhD, and Travis Bernardo, PhD, of Regeneron Pharmaceuticals Inc. assisted in reviewing the manuscript. The study was supported by Regeneron Pharmaceuticals, Inc. and F. Hoffmann-La Roche Ltd. 


\section{References}

1 Ludwig S, Zarbock A. Coronaviruses and SARS-CoV-2: a brief overview. Anesth Analg 2020; 131: 93-6.

2 Li Q, Guan X, Wu P, et al. Early Transmission Dynamics in Wuhan, China, of Novel Coronavirus-Infected Pneumonia. N Engl J Med 2020; 382: 1199-207.

3 Wu C, Chen X, Cai Y, et al. Risk factors associated with acute respiratory distress syndrome and death in patients with coronavirus disease 2019 pneumonia in Wuhan, China. JAMA Intern Med 2020; 180: 934-43.

4 Chen N, Zhou M, Dong X, et al. Epidemiological and clinical characteristics of 99 cases of 2019 novel coronavirus pneumonia in Wuhan, China: a descriptive study. Lancet 2020; 395: 507-13.

5 Centers for Disease Control and Prevention. Coronavirus disease 2019 (COVID-19): people with certain medical conditions. 2020. https://www.cdc.gov/coronavirus/2019-ncov/need-extra-precautions/peoplewith-medical-conditions.html (accessed November 11, 2020).

6 Lighter J, Phillips M, Hochman S, et al. Obesity in patients younger than 60 years is a risk factor for COVID-19 hospital admission. Clin Infect Dis 2020; 71: 896-7.

7 Magleby R, Westblade LF, Trzebucki A, et al. Impact of SARS-CoV-2 viral load on risk of intubation and mortality among hospitalized patients with coronavirus disease 2019. Clin Infect Dis 2020: ciaa851. doi: $10.1093 /$ cid/ciaa851. Online ahead of print.

8 Westblade LF, Brar G, Pinheiro LC, et al. SARS-CoV-2 Viral Load Predicts Mortality in Patients with and without Cancer Who Are Hospitalized with COVID-19. Cancer Cell 2020; 38: 661-71.e2. 
$9 \quad$ Huang C, Wang Y, Li X, et al. Clinical features of patients infected with 2019 novel coronavirus in Wuhan, China. Lancet 2020; 395: 497-506.

10 Jiang S, Hillyer C, Du L. Neutralizing Antibodies against SARS-CoV-2 and Other Human Coronaviruses. Trends Immunol 2020; 41: 355-9.

11 Copin R, Baum A, Wloga E, et al. The monoclonal antibody combination REGEN-COV protects against SARS-CoV-2 mutational escape in preclinical and human studies. Cell 2021; 184: 3949-61 e11.

12 Hansen J, Baum A, Pascal KE, et al. Studies in humanized mice and convalescent humans yield a SARS-CoV-2 antibody cocktail. Science 2020; 369: 1010-4.

13 Wang P, Nair MS, Liu L, et al. Antibody resistance of SARS-CoV-2 variants B.1.351 and B.1.1.7. Nature 2021; 593: 130-5.

14 Weinreich DM, Sivapalasingam S, Norton T, et al. REGN-COV2, a neutralizing antibody cocktail, in outpatients with Covid-19. N Engl J Med $2021 ; 384: 238-51$.

15 Regeneron Pharmaceuticals Inc. Regeneron's casirivimab and imdevimab antibody cocktail for COVID-19 is first combination therapy to receive FDA emgency use authorization. 2020. https://investor.regeneron.com/newsreleases/news-release-details/regenerons-regen-cov2-first-antibody-cocktailcovid-19-receive (accessed April 7, 2021).

16 U.S. Food \& Drug Administration. Letter of authorization for emergency use of REGEN-COV (casirivimab with imdevimab). September 92021.

https://www.fda.gov/media/145610/download (accessed October 20, 2021).

17 Weinreich DM, Sivapalasingam S, Norton T, et al. REGEN-COV Antibody Cocktail in Outpatients with Covid-19. medRxiv 2021: 2021.06.09.21257915. 
medRxiv preprint doi: https://doi.org/10.1101/2021.11.09.21265912; this version posted November 10, 2021. The copyright holder for this preprint (which was not certified by peer review) is the author/funder, who has granted medRxiv a license to display the preprint in perpetuity. It is made available under a CC-BY-NC-ND 4.0 International license .

18 O'Brien MP, Forleo-Neto E, Musser BJ, et al. Subcutaneous REGEN-COV Antibody Combination to Prevent Covid-19. N Engl J Med 2021; 385: 118495.

19 US Food and Drug Administration. Fact sheet for health care providers Emergency Use Authorization (EUA) of REGEN-COV ${ }^{\mathrm{TM}}$ (casirivimab and imdevimab). June 2021. https://www.fda.gov/media/145611/download (accessed June 24, 2021). 


\section{Table 1: Demographics and baseline characteristics for seronegative mFAS IV patients and SC patients}

\begin{tabular}{|c|c|c|c|c|c|c|c|c|c|}
\hline & \multicolumn{6}{|c|}{ IV } & \multicolumn{3}{|c|}{ sc } \\
\hline Age (years) & $35.1(9.97)$ & $\begin{array}{c}33 \cdot 8 \\
(8 \cdot 90)\end{array}$ & $33.9(9.16)$ & $34.1(10.51)$ & $36 \cdot 3(9 \cdot 16)$ & $34.6(9.55)$ & $33.5(9.18)$ & $33.5(10.88)$ & $34.1(10 \cdot 00)$ \\
\hline \multicolumn{10}{|l|}{ Sex } \\
\hline \multicolumn{10}{|l|}{ Ethnicity } \\
\hline Hispanic/Latino & $27(35 \cdot 1 \%)$ & $\begin{array}{c}28 \\
(35 \cdot 0 \%)\end{array}$ & $16(23 \cdot 5 \%)$ & $26(36 \cdot 1 \%)$ & $24(38 \cdot 7 \%)$ & $121(33 \cdot 7 \%)$ & $30(40 \cdot 0 \%)$ & $21(28.8 \%)$ & $78(34.7 \%)$ \\
\hline Not Hispanic/Latino & $50(64.9 \%)$ & $\begin{array}{c}52 \\
(65 \cdot 0 \%)\end{array}$ & $52(76 \cdot 5 \%)$ & $43(59 \cdot 7 \%)$ & $38(61.3 \%)$ & $235(65 \cdot 5 \%)$ & 44 (58.7\%) & $50(68 \cdot 5 \%)$ & $144(64 \cdot 0 \%)$ \\
\hline \multicolumn{10}{|l|}{ Race } \\
\hline White & 64 (83.1\%) & $\begin{array}{c}71 \\
(88.8 \%)\end{array}$ & 63 (92.6\%) & 56 (77.8\%) & $55(88.7 \%)$ & $309(86.1 \%)$ & 67 (89.3\%) & $59(80 \cdot 8 \%)$ & $190(84 \cdot 4 \%)$ \\
\hline Black & $\begin{array}{c}2 \\
(2 \cdot 6 \%)\end{array}$ & $\begin{array}{c}3 \\
(3.8 \%)\end{array}$ & $\begin{array}{c}2 \\
(2 \cdot 9 \%)\end{array}$ & $\begin{array}{c}3 \\
(4 \cdot 2 \%)\end{array}$ & $\begin{array}{c}4 \\
(6.5 \%)\end{array}$ & $14(3.9 \%)$ & $2(2 \cdot 7 \%)$ & $2(2 \cdot 7 \%)$ & $6(2 \cdot 7 \%)$ \\
\hline Asian & $10(13 \cdot 0 \%)$ & $\begin{array}{c}2 \\
(2.5 \%)\end{array}$ & $\begin{array}{c}2 \\
(2 \cdot 9 \%)\end{array}$ & $\begin{array}{c}7 \\
(9.7 \%)\end{array}$ & $\begin{array}{c}2 \\
(3 \cdot 2 \%)\end{array}$ & $23(6 \cdot 4 \%)$ & $5(6 \cdot 7 \%)$ & $9(12 \cdot 3 \%)$ & $24(10 \cdot 7 \%)$ \\
\hline $\begin{array}{l}\text { American Indian or } \\
\text { Alaska Native }\end{array}$ & 0 & $2(2 \cdot 5 \%)$ & $1(1.5 \%)$ & 0 & 0 & $3(0.8 \%)$ & 0 & 0 & 0 \\
\hline Unknown & 0 & 0 & 0 & $1(1.4 \%)$ & 0 & $1(0.3 \%)$ & 0 & $1(1.4 \%)$ & $1(0.4 \%)$ \\
\hline
\end{tabular}




\begin{tabular}{|c|c|c|c|c|c|c|c|c|c|c|}
\hline Not reported & $1(1.3 \%)$ & 2 (2.5\%) & 0 & 5 (6.9\%) & $1(1 \cdot 6 \%)$ & $9(2.5 \%)$ & $1(1.3 \%)$ & $2(2 \cdot 7 \%)$ & $4(1 \cdot 8 \%)$ & \\
\hline Weight (kg) & $74 \cdot 0(16 \cdot 0)$ & $\begin{array}{c}73 \cdot 1 \\
(14 \cdot 0)\end{array}$ & $73 \cdot 1(13 \cdot 5)$ & $73.1(13.5)$ & $73 \cdot 2(12 \cdot 3)$ & $73.3(13.9)$ & $72 \cdot 8(12 \cdot 5)$ & $74.5(13.5)$ & $73 \cdot 8(14 \cdot 1)$ & \\
\hline $\begin{array}{l}\text { SARS-CoV-2 results } \\
\text { from central lab, NP } \\
\text { swab (log }{ }_{10} \text { copies/mL) }\end{array}$ & $7 \cdot 0(1.4)$ & $7 \cdot 2(1 \cdot 6)$ & $7 \cdot 4(1.5)$ & $7 \cdot 2(1.5)$ & $7 \cdot 3(1 \cdot 6)$ & $7 \cdot 2(1.5)$ & $7 \cdot 4(1.5)$ & $7 \cdot 2(1 \cdot 6)$ & $7 \cdot 2(1.5)$ & \\
\hline $\begin{array}{l}\text { Baseline viral load } \\
\text { categories, copies/mL }\end{array}$ & & & & & & & & & & $\begin{array}{l}\bar{F} \\
\bar{\omega} \\
\overline{3} \\
\mathscr{2}\end{array}$ \\
\hline$>10^{3}$ & $\begin{array}{c}77 \\
(100 \%)\end{array}$ & $\begin{array}{c}79 \\
(98 \cdot 8 \%)\end{array}$ & 68 (100\%) & 72 (100\%) & 62 (100\%) & 358 (99.7\%) & 73 (97.3\%) & 72 (98.6\%) & $222(98 \cdot 7 \%)$ & 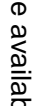 \\
\hline$>10^{4}$ & 76 (98.7\%) & $\begin{array}{c}78 \\
(97 \cdot 5 \%)\end{array}$ & 66 (97.1\%) & 70 (97.2\%) & 60 (96.8\%) & 350 (97.5\%) & 73 (97.3\%) & 71 (97.3\%) & $220(97 \cdot 8 \%)$ & $\begin{array}{l}\frac{\sigma}{\Phi} \\
\frac{5}{0} \\
\frac{0}{0}\end{array}$ \\
\hline$>10^{5}$ & 72 (93.5\%) & $\begin{array}{c}72 \\
(90 \cdot 0 \%)\end{array}$ & 63 (92.6\%) & $66(91.7 \%)$ & 55 (88.7\%) & 328 (91.4\%) & 70 (93.3\%) & 64 (87.7\%) & $206(91 \cdot 6 \%)$ & ?ֶ \\
\hline$>10^{7}$ & 38 (49.4\%) & $\begin{array}{c}48 \\
(60 \cdot 0 \%)\end{array}$ & 42 (61.8\%) & 40 (55.6\%) & 36 (58.1\%) & $204(56 \cdot 8 \%)$ & 49 (65.3\%) & 41 (56·2\%) & 128 (56.9\%) & $\begin{array}{l}\text { पे } \\
+ \\
0\end{array}$ \\
\hline $\begin{array}{l}\text { Below lower limit of } \\
\text { quantification }\end{array}$ & 0 & $1(1.3 \%)$ & 0 & 0 & 0 & $1(0 \cdot 3 \%)$ & 2 (2.7\%) & 0 & 2 (0.9\%) & 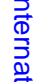 \\
\hline \multicolumn{11}{|c|}{ 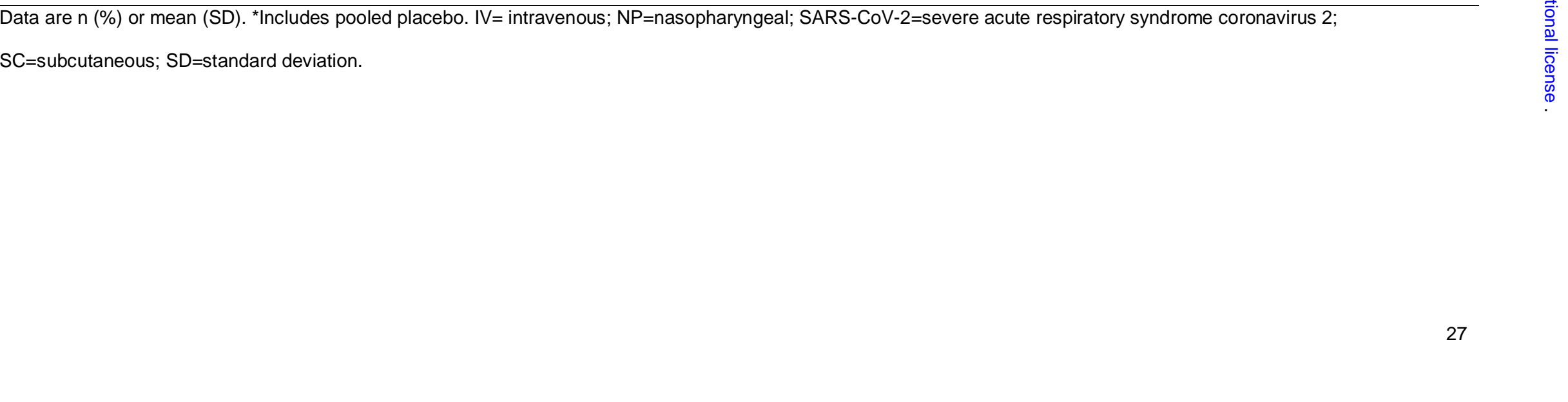 } \\
\hline
\end{tabular}


Table 2: Adverse events in the safety population* in IV patients and SC patients

\begin{tabular}{|c|c|c|c|c|c|c|c|c|c|}
\hline & & & IV & & & & sc & & \\
\hline & $\begin{array}{l}\text { Placebo IV } \\
(n=57)\end{array}$ & $\begin{array}{l}\text { REGEN-COV } \\
300 \mathrm{mg} \mathrm{IV} \\
(\mathrm{n}=115)\end{array}$ & $\begin{array}{l}\text { REGEN-COV } \\
600 \mathrm{mg} \mathrm{IV} \\
(\mathrm{n}=114)\end{array}$ & $\begin{array}{l}\text { REGEN-COV } \\
1200 \mathrm{mg} \text { IV } \\
(\mathrm{n}=116)\end{array}$ & $\begin{array}{l}\text { REGEN-COV } \\
2400 \mathrm{mg} \text { IV } \\
(\mathrm{n}=115)\end{array}$ & $\begin{array}{l}\text { Placebo SC } \\
\quad(n=58)\end{array}$ & $\begin{array}{l}\text { REGEN-COV } \\
600 \mathrm{mg} \mathrm{SC} \\
(\mathrm{n}=114)\end{array}$ & $\begin{array}{c}\text { REGEN-COV } \\
1200 \mathrm{mg} \mathrm{SC} \\
(\mathrm{n}=114)\end{array}$ & \\
\hline Patients with any TEAE & $10(17 \cdot 5 \%)$ & $10(8 \cdot 7 \%)$ & $16(14 \cdot 0 \%)$ & $22(19 \cdot 0 \%)$ & $9(7 \cdot 8 \%)$ & $6(10 \cdot 3 \%)$ & $5(4 \cdot 4 \%)$ & $12(10 \cdot 5 \%)$ & 3 \\
\hline $\begin{array}{l}\text { Patients with any grade } 3 / 4 \\
\text { TEAE }\end{array}$ & $1(1 \cdot 8 \%)$ & 0 & $1(0.9 \%)$ & $1(0.9 \%)$ & 0 & 0 & 0 & 0 & פֶ. \\
\hline Patients with any SAE & 0 & 0 & 0 & $1(0.9 \%)$ & $1(0.9 \%)$ & 0 & 0 & 0 & $\frac{\sigma}{D}$ \\
\hline Patients with any AESI & $1(1 \cdot 8 \%)$ & 0 & $1(0.9 \%)$ & $2(1 \cdot 7 \%)$ & 0 & 0 & 0 & $1(0.9 \%)$ & $\frac{0}{\mathbb{D}}$ \\
\hline Patients with any serious AESI & 0 & 0 & 0 & 0 & 0 & 0 & 0 & 0 & อి \\
\hline $\begin{array}{l}\text { Patients with infusion-related } \\
\text { reaction (grade } \geq 2 \text { ) through day } \\
4\end{array}$ & 0 & 0 & 0 & 0 & 0 & 0 & 0 & 0 & $\sum_{\substack{1 \\
⿱ \\
z}}^{w}$ \\
\hline $\begin{array}{l}\text { Patients with injection-site } \\
\text { reactions (grade } \geq 3 \text { ) through } \\
\text { day } 4\end{array}$ & 0 & 0 & 0 & 0 & 0 & 0 & 0 & 0 & 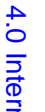 \\
\hline $\begin{array}{l}\text { Patients with hypersensitivity } \\
\text { reactions (grade } \geq 2 \text { ) through } \\
\text { day } 29\end{array}$ & 0 & 0 & 0 & 0 & 0 & 0 & 0 & 0 & 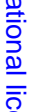 \\
\hline $\begin{array}{l}\text { Patients with any TEAE leading } \\
\text { to death }\end{array}$ & 0 & 0 & 0 & 0 & 0 & 0 & 0 & 0 & लD \\
\hline $\begin{array}{l}\text { Patients with any TEAE leading } \\
\text { to withdrawal from the study } \\
\text { medication }\end{array}$ & 0 & 0 & 0 & 0 & $1(0.9 \%)$ & 0 & 0 & 0 & \\
\hline $\begin{array}{l}\text { Patients with any TEAE leading } \\
\text { to study infusion interruption }\end{array}$ & 0 & 0 & 0 & 0 & 0 & 0 & 0 & 0 & \\
\hline
\end{tabular}


Data are $\mathrm{n}(\%)$. *The safety population includes all randomised patients who received any study drug. AESI=adverse event of special interest; IV=intravenous; SAE=serious adverse event; $\mathrm{SC}=$ subcutaneous; TEAE=treatment-emergent adverse event. 
medRxiv preprint doi: https://doi.org/10.1101/2021.11.09.21265912; this version posted November 10, 2021. The copyright holder for this preprint (which was not certified by peer review) is the author/funder, who has granted medRxiv a license to display the preprint in perpetuity.

It is made available under a CC-BY-NC-ND 4.0 International license .

Figure 1: Study design

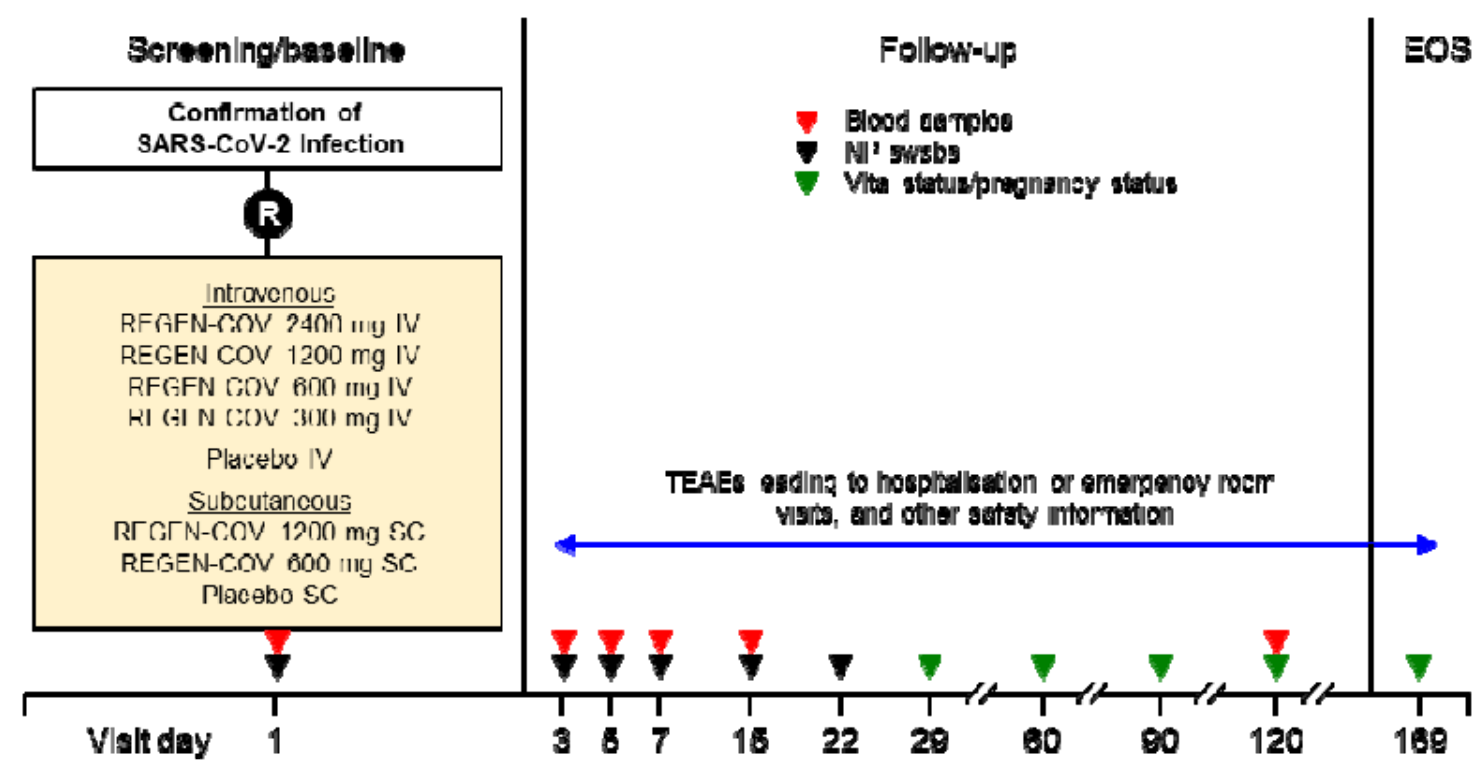

EOS=end of study; IV=intravenous; NP=nasopharyngeal; R=randomisation; SARS-CoV-2=severe acute respiratory syndrome coronavirus 2 ; $\mathrm{SC}=$ subcutaneous; TEAE=treatment-emergent adverse event. 
Figure 2: Pairwise comparisons in the seronegative population of TWACB from day 1 to day 7 for each active treatment group versus $(A)$ pooled placebo in the mFAS population or (B) another active treatment group in the PPS population

$\mathbf{A}$

\begin{tabular}{|c|c|c|}
\hline Treatment vs placebo & $\begin{array}{c}\text { LS mean } \\
\text { dlfference }(95 \% \mathrm{Cl})\end{array}$ & p-value \\
\hline $2400 \mathrm{mg}$ IV vs placebo & $-0.71(-1.05,-0.38)$ & $<0.0001$ \\
\hline $1200 \mathrm{mg}$ IV vs placebo & $-0.56(-0.89,-0.24)$ & 0.0007 \\
\hline $1200 \mathrm{mg}$ SC vs placebo & $-0.56(-0.87,-0.24)$ & 0.0007 \\
\hline $600 \mathrm{mg}$ IV vs placebo & $-0.66(-0.99,-0.34)$ & $<0.0001$ \\
\hline $600 \mathrm{mg} S \mathrm{~S}$ vs placebo & $-0.56(-0.88,-0.24)$ & 0.0006 \\
\hline $300 \mathrm{mg}$ IV vs placebo & $-0.57(-0.88,-0.25)$ & 0.0004 \\
\hline
\end{tabular}

$\mathbf{B}$

\begin{tabular}{|c|c|}
\hline reatment $A$ vs treatment $B$ & $\begin{array}{c}\text { LS means } \\
\text { dlfference }(95 \% \mathrm{Cl})\end{array}$ \\
\hline 400 mg IV vs 1200 mg IV & $-0.16(-0.50,0.18)$ \\
\hline $100 \mathrm{mg}$ IV vs $1200 \mathrm{mg}$ SC & $-0.17(-0.50,0.17)$ \\
\hline $400 \mathrm{mg}$ IV vs $600 \mathrm{mg}$ IV & $-0.06(-0.40,0.28)$ \\
\hline $2400 \mathrm{mg}$ IV vs $600 \mathrm{mg}$ SC & $-0.16(-0)$ \\
\hline $2400 \mathrm{mg}$ IV vs $300 \mathrm{mg}$ IV & $-0.15(-0.48,0.18)$ \\
\hline $1200 \mathrm{mg}$ IV vs $1200 \mathrm{mg} \mathrm{SC}$ & $-0.01(-0.33,0.32)$ \\
\hline $1200 \mathrm{mg}$ IV vs $600 \mathrm{mg}$ IV & $0.1(-0.23,0.43)$ \\
\hline $1200 \mathrm{mg}$ IV vs $600 \mathrm{mg}$ SC & $0(-0$ \\
\hline $1200 \mathrm{mg}$ IV vs $300 \mathrm{mg}$ IV & $0.01(-0.31,0.33)$ \\
\hline $1200 \mathrm{mg}$ SC vs $600 \mathrm{mg}$ IV & $0.11(-0.22,0.43)$ \\
\hline $1200 \mathrm{mg} \mathrm{SC}$ vo $600 \mathrm{mg} \mathrm{SC}$ & $0(-0.32,0.33)$ \\
\hline $1200 \mathrm{mg} \mathrm{SC} \mathrm{va} 300 \mathrm{mg}$ IV & $0.01(-0.30,0.33)$ \\
\hline $600 \mathrm{mg}$ IV vs $600 \mathrm{mg}$ SC & $-0.1(-0.43,0.23)$ \\
\hline $600 \mathrm{mg}$ IV vs $300 \mathrm{mg}$ IV & $-0.08(-0.42,0.23)$ \\
\hline $600 \mathrm{mg}$ SC v $300 \mathrm{mg}$ IV & $0.01(-0.31,0.32)$ \\
\hline
\end{tabular}

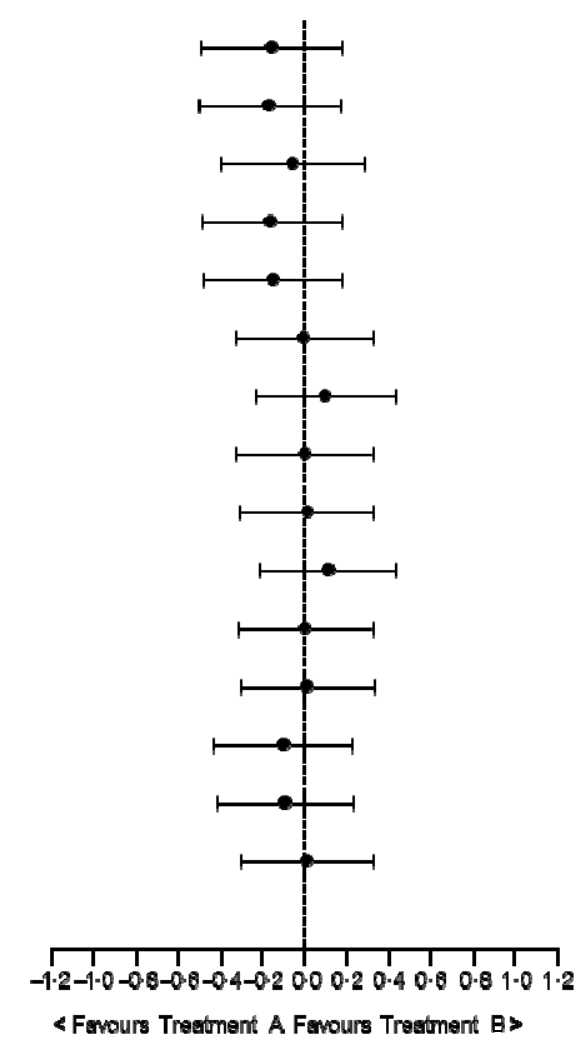


medRxiv preprint doi: https://doi.org/10.1101/2021.11.09.21265912; this version posted November 10, 2021. The copyright holder for this preprint (which was not certified by peer review) is the author/funder, who has granted medRxiv a license to display the preprint in perpetuity.

It is made available under a CC-BY-NC-ND 4.0 International license .

$\mathrm{Cl}=$ confidence interval; IV=intravenous; LS=least squares; $\mathrm{mFAS}=$ modified full analysis set; PPS=per protocol set; $\mathrm{SC}=$ subcutaneous; TWACB=time-weighted average change from baseline. 
medRxiv preprint doi: https://doi.org/10.1101/2021.11.09.21265912; this version posted November 10, 2021. The copyright holder for this preprint (which was not certified by peer review) is the author/funder, who has granted medRxiv a license to display the preprint in perpetuity.

It is made available under a CC-BY-NC-ND 4.0 International license .

Figure 3: LS mean ( \pm SE) change from baseline in viral load of IV and SC doses at each visit in the seronegative mFAS population

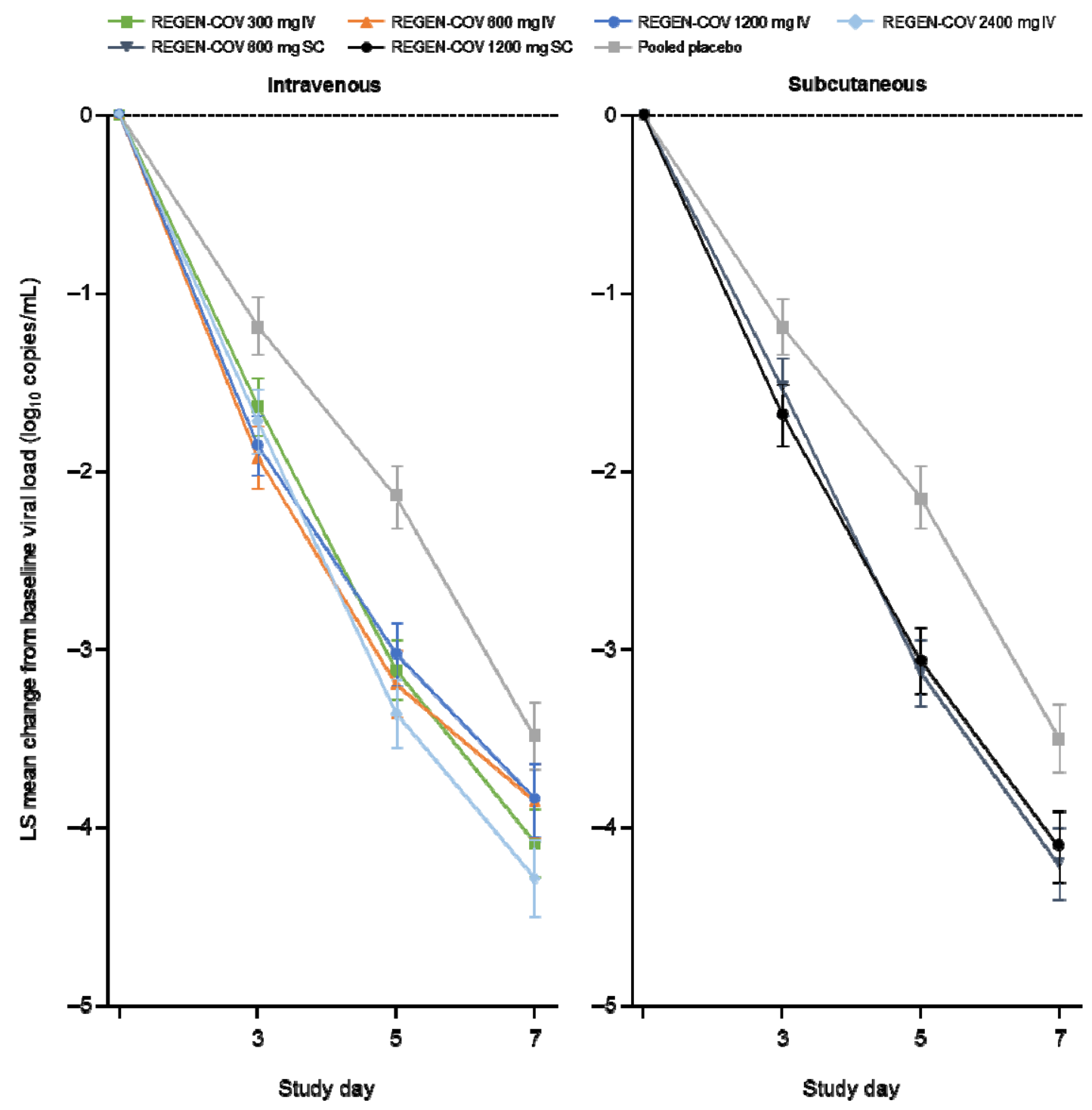

IV=intravenous; LSM=least-squares mean; mFAS=modified full analysis set; SC=subcutaneous; $\mathrm{SE}=$ standard error. 
medRxiv preprint doi: https://doi.org/10.1101/2021.11.09.21265912; this version posted November 10, 2021. The copyright holder for this preprint (which was not certified by peer review) is the author/funder, who has granted medRxiv a license to display the preprint in perpetuity.

It is made available under a CC-BY-NC-ND 4.0 International license .

Figure 4: Mean (+SD) total REGEN-COV concentrations in serum in nominal time after single IV and SC doses

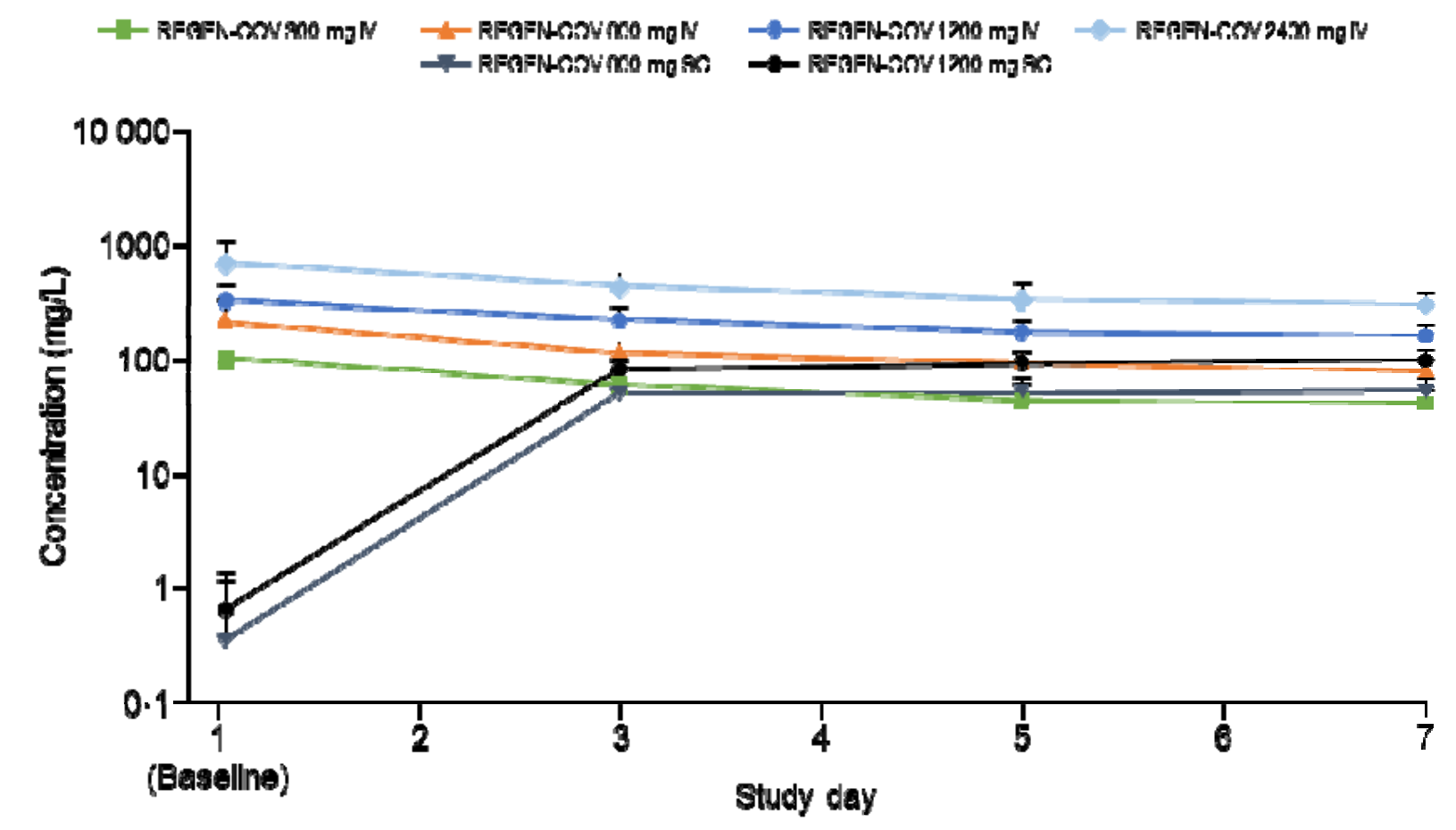

$\mathrm{IV}=$ intravenous; SC=subcutaneous; SD=standard deviation. 
Figure 5: TWACB in viral load $\left(\log _{10}\right.$ copies $\left./ \mathrm{mL}\right)$ versus total REGEN-COV concentrations* in serum in individual patients at days 3,5 , and 7 for (A) IV and (B) SC treatment groups (mCRAS)

$\mathbf{A}$
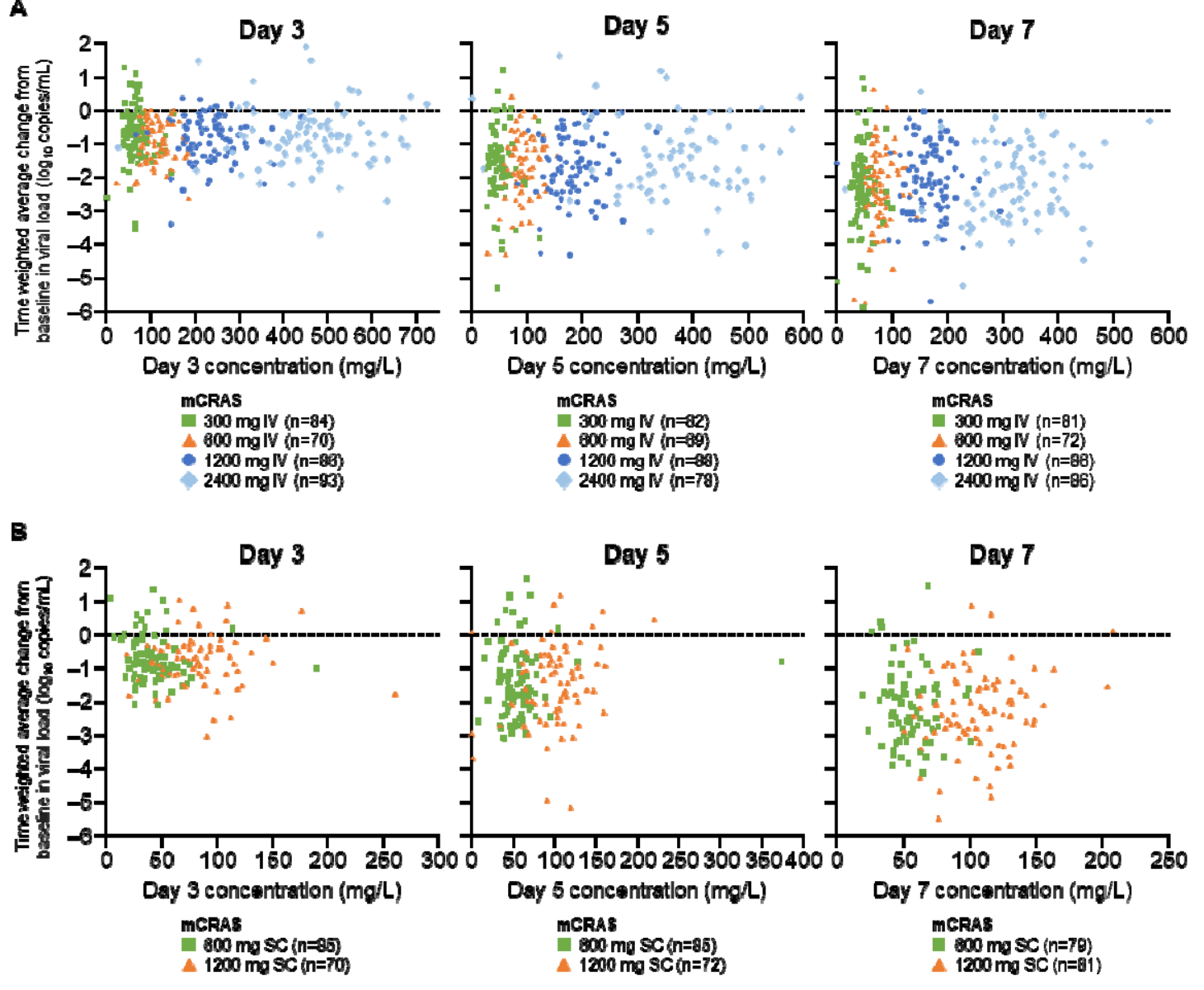

${ }^{*}$ Total REGEN-COV concentration is the sum of total casirivimab and total imdevimab concentrations in serum.

$\mathrm{IV}=$ intravenous; $\mathrm{mCRAS}=$ modified concentration-response analysis set; $\mathrm{SC}=$ subcutaneous; TWACB=time-

weighted average change from baseline. 